\title{
Property Prices and Exposure to Multiple Noise Sources: Hedonic Regression with Road and Railway Noise ${ }^{\star}$
}

\author{
Henrik Andersson ${ }^{1, \star \star}$, Lina Jonsson ${ }^{2}$, Mikael Ögren ${ }^{3}$ \\ 1 Toulouse School of Economics (LERNA), Toulouse, France \\ 2 Department of Transport Economics, Swedish National Road and Transport Research Institute (VTI), \\ Stockholm, Sweden \\ 3 Department of Environment and Traffic Analysis, VTI, Gothenburg, Sweden
}

June 28, 2009

\begin{abstract}
This study examines the effect of road and railway noise on property prices. It uses the hedonic regression technique on a Swedish data set that contains information about both road and railway noise for each property, and finds that road noise has a larger negative impact on the property prices than railway noise. This is in line with the evidence from the acoustical literature which has shown that individuals are more disturbed by road than railway noise, but contradicts recent results from a hedonic study on data of the United Kingdom.
\end{abstract}

Key words Hedonic Pricing; Noise; Railway Traffic; Road Traffic

JEL codes C13; C21; Q51; Q53

* This study was funded by Banverket and Vägverket, and the financial support is gratefully acknowledged. The authors are solely responsible for the results and views expressed in this paper.

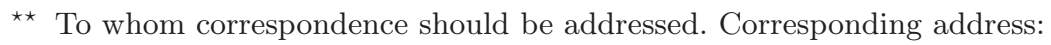

Toulouse School of Economics, 21 all.de Brienne, Aile J.J. Laffont, 31042 Toulouse, France, e-mail: henrik. andersson@tse-fr.eu 


\section{Introduction}

It has been suggested that more than 20 percent of the population of the European Union (EU) are exposed to higher noise levels than considered acceptable (European Commission, 1996). Noise is an environmental and health problem of major concern in many developed countries, and one of the major sources of noise exposure is the transport sector. Noise from this sector is problematic for, broadly speaking, two reasons: (i) increasing transportation of goods and people means higher noise levels, and (ii) since transport is related to human activity and needs, much of it occurs in areas where people live, work, go to school, etc. The latter means that today's urbanization will lead to noise being a bigger problem in the future unless efforts are made to mitigate the problem (Nijland et al., 2003).

Such efforts come at a cost, though, and policies and projects to reduce noise levels need to be evaluated to secure an efficient resource allocation. Benefit cost analysis (BCA) is a powerful tool to evaluate noise abatement, but it requires both benefits and costs to be measured in a common metric. Moreover, the EU has decided that infrastructure charges should be based on short-run marginal costs (European Commission, 1998), which has the potential to internalize external effects of traffic. Such charges also require monetary values. To monetize the social value of changes in noise levels, analysts rely on non-marketed good evaluation techniques, and the technique that dominates is Rosen's hedonic regression method (Rosen, 1974).

Most studies monetizing noise have focused on road and air noise (Arsenio et al., 2006; Bateman et al., 2001; Garrod et al., 2002; Navrud, 2004; Nelson, 1982, 2004). This study examines the willingness to pay (WTP) to reduce road and railway noise. It is a well established fact in the acoustic literature that, for the same level of the noise indicator, individuals are more annoyed by road than by railway noise (Miedema and Oudshoorn, 2001). ${ }^{1}$ However, in a recent study using the hedonic regression technique in the UK, Day et al. (2007) found that the WTP among property owners to reduce railway noise was higher compared with road noise. This conflicting evidence is interesting since the evidence from the acoustic literature is based on individuals' stated annoyance from different noise sources, whereas the evidence in Day et al. is based on actual decisions by property owners.

This study examines how property prices are affected by multiple noise sources, in this case road and railway noise. The aims are: (i) to ascertain whether the findings in Day et al. (2007) are robust for the revealed preference literature or whether the WTP is more in line with the findings in the acoustical literature, and (ii) to estimate the WTP to reduce road and railway noise that could be considered in policy implementation. The first aim is of great interest from both a research and policy perspective

1 The evidence also suggests that individuals are more annoyed by air than road noise (Miedema and Oudshoorn, 2001). 
since it examines how individuals' stated preferences (non-binding) agree with their actual behavior. The second aim is mainly of policy interest, since it examines the need for differentiated values in BCA or infrastructure charges (Andersson and Ögren, 2007a,b). We employ the hedonic regression technique on a municipality in the west of Sweden.

The article is organized as follows. Section 2 briefly describes the hedonic regression technique. Sections 3,4 , and 5 contain the data used, the econometric models, and the results. The final section discusses our findings and relates them to other results in the literature.

\section{The hedonic regression technique}

In his seminal paper, Sherwin Rosen (Rosen, 1974) showed that in an economy with utility and profit maximizing individuals and firms, the marginal WTP for attributes of composite goods will equal their implicit prices. $^{2}$

Considering the scenario of interest in this study, where our composite good is a property, let $L$ and $\mathbf{A}=\left[a_{1}, \ldots, a_{n}\right]$ denote noise and a vector of other utility-bearing attributes. The hedonic price function $(P)$ may then be written as

$$
P=P(L, \mathbf{A}) .
$$

Rosen showed that the consumer's WTP for the good will equal its market price. Since, in optimum, the consumer's marginal WTP equals his marginal rate of substitution between the price of the good and any of the attributes, the slope of the price function may be used to determine the consumer's marginal WTP. Focusing on noise, the marginal WTP is, thus, estimated as

$$
\operatorname{MWTP}=\frac{\partial P(L, \mathbf{A})}{\partial L}
$$

The information about individuals' preferences from Eq. (2) only reveals the marginal WTP in optimum; it does not reveal the underlying preference structure. To derive the price function and to estimate the marginal WTP using the hedonic regression technique is sometimes referred to as the first step of the technique. In the second step, where the preference parameters are estimated, the results from the first step, together with information on property owners/households, are used. The second step enables the analyst to calculate "theoretically consistent" values for non-marginal changes, which was done in Day et al. (2007). In this study only the first step is conducted.

\footnotetext{
2 The hedonic regression technique has been discussed in several articles, books and book chapters (Bateman et al., 2001; Freeman, 2003; Haab and McDonnel, 2003; Ekeland et al., 2004; Palmquist, 2005; Andersson, 2008), and we therefore only give a brief introduction to the technique here. For a more comprehensive description of the technique, see references provided or the original source (Rosen, 1974).
} 


\section{Data}

This study estimates the impact of traffic noise from both railway and roads on property prices in the municipality of Lerum close to Gothenburg in the west of Sweden. Lerum has about 36,000 inhabitants and a population density of 138 inhabitants per $\mathrm{km}^{2}$. Two major transport routes connecting Gothenburg and Stockholm cross the municipality: the railway line Västra stambanan and the motorway E20. Figure 1 shows a sketch over the survey area with the two transport routes.

[Figure 1 about here.]

The data set used in this study originates from two sources. The data on the property prices and attributes (besides the noise levels) are from the National Land Survey of Sweden and are used for property taxation. The property attributes also contain the geographical coordinates, which are used here to derive geographical variables like neighborhood dummies and distance to nearest train station and highway entrance. The data set covers all the sales of single family houses in the municipality of Lerum from the autumn of 1996 to early 2006. Since the data covers a period of several years, the property prices have been adjusted to the property price index of the Gothenburg region and are shown at 2004 price levels. In the regression, the sale closest to January 1st 2004 is used for those properties that were sold several times during the period.

Information about noise levels is from a study on the health effects of traffic noise conducted in Lerum in 2004 (Öhrström et al., 2005). Separate noise calculations were made for railway and road noise for all the houses in Lerum.

Descriptive statistics for the different variables are shown in Table 1. The following three sections describe the groups of variables used as explanatory variables in the price equations, followed by a section describing the exclusion criteria used in the regressions.

[Table 1 about here.]

\subsection{Structural variables}

Structural variables define the character of the property, and those used in the regressions are property type, living space and a quality index that is based on a self-reported form that the house owner fills in for the tax assessment. The quality index is based on questions concerning the indoor-quality of the property, for instance the standard of the kitchen, the existence of an open fire place or a sauna, etc. The buildings are categorized as detached, linked by a garage or terraced. 


\subsection{Geographical attributes}

The geographical variables included in the study are all derived from the coordinates of each property. All the properties are distributed over 11 districts based on their distance to the five commuter train stations in the municipality. The commuter train stations are centrally situated in distinct neighborhoods and the district variables are constructed in a way that divides properties into two groups depending on whether they are $1 \mathrm{~km}$ or between 1 and $2 \mathrm{~km}$ from the nearest station. For properties more than $2 \mathrm{~km}$ from the nearest station a separate district is created, Country side. Moreover, a variable measuring the distance to the nearest commuter train station using the road network is included to further capture the accessibility to train and to other community services located close to the train stations. A dummy that equals one for the properties within 150 meters from the motorway E20 is included to control for other disadvantages (or possibly advantages), apart from noise, of living close to a major road, like effects on air quality. To capture accessibility by car, the distance by road to the nearest entrance to the motorway E20 is also included in the models.

\subsection{Noise indicator}

The most commonly used noise indicator is the A-weighted equivalent sound pressure level, which is an energy average over a certain time period, normally 24 hours and then denoted $L_{\mathrm{AEq}, 24 \mathrm{~h}}$. The A-weighting approximates the varying sensitivity of the human ear to different frequencies. The equivalent level is a good indicator of overall annoyance, but for sleep disturbance a better choice is the maximum level, which is normally defined as the maximum noise level occurring during a certain time period. The maximum level is more difficult to predict using calculation methods, and has a complex dependence on the traffic volume since a noisy vehicle may be present even in low traffic conditions (see Sandberg and Ejsmont, 2002). We will, therefore, focus on the equivalent level in this study.

In Öhrström et al. (2005) equivalent noise levels $\left(L_{\mathrm{AEq}, 24 \mathrm{~h}}\right)$ were calculated for each property separately for both rail and road noise using the "Nordic methods" (Jonasson and Nielsen, 1996; Nielsen, 1996). For each residential building the façade with the highest noise level was chosen to represent the property, which meant that the rail noise and the road noise for some properties occurred at different façades. The noise variables were calculated in 2003 and reflected the noise level for that particular year, but the effect of traffic changes is limited if expressed in terms of changed noise level. ${ }^{3}$

The dB-scale used for all noise variables in this study does not have a natural zero point; instead, the zero of the scale is determined by convention (see Sandberg and Ejsmont, 2002). The sound pressure

\footnotetext{
3 Approximately $1 \mathrm{~dB}$ for a $30 \%$ traffic increase over 10 years
} 
level $0 \mathrm{~dB}$ corresponds to a sound pressure of $20 \mu \mathrm{Pa}$, which is roughly the lowest audible level for a tonal sound at a frequency of $1000 \mathrm{~Hz}$. The total absence of sound is represented by a sound pressure of $0 \mathrm{~Pa}$, corresponding to negative infinity on the $\mathrm{dB}$ scale $(-\infty \mathrm{dB})$. For other environmental effects it makes sense to use valuations that vanish when the effect variable becomes zero (for instance, number of particles per $\mathrm{m}^{3}$ describing air pollution), but the same is not true for noise measured in dBs. The effect should be zero when no negative effect is observed from noise, and in our study we have chosen to use a lower limit of $L_{\mathrm{AEq}, 24 \mathrm{~h}}=45 \mathrm{~dB}$. The limit is somewhat arbitrarily determined, but the percentage of persons reporting that they are annoyed by traffic noise is very low below this level (Miedema and Oudshoorn, 2001). Therefore, the noise variables in our hedonic regressions are defined by the absolute noise level minus 45 , with 0 for levels below $45 \mathrm{~dB}$.

\subsection{Included observations}

As mentioned above, we assume that equivalent noise levels below $45 \mathrm{~dB}$ do not influence the property prices. However, to get a more homogeneous sample we include only properties with a total noise level that is assumed to be disturbing. As thresholds we use two levels, 50 and $55 \mathrm{~dB}$. The first $(50 \mathrm{~dB})$ is the official Swedish threshold value, i.e. the official Swedish cost function from noise exposure is zero for noise levels below $50 \mathrm{~dB}$ (SIKA, 2008). The latter $(55 \mathrm{~dB})$ is often used by authorities as a limit value below which no measures are taken to mitigate the noise (Nijland and Van Wee, 2005). By using two threshold levels, we also examine how sensitive our regression results are to the chosen level. The threshold level is based on the total equivalent noise level, which is calculated as

$$
L_{\text {tot }}\left(L_{1}, L_{2}\right)=10 \log \left(10^{\frac{L_{1}}{10}}+10^{\frac{L_{2}}{10}}\right) .
$$

where $L_{j}, j \in\{1,2\}$, represent the equivalent noise level in $\mathrm{dB}$ from road (1) and rail (2) traffic noise, respectively. When $L_{1}$ and $L_{2}$ are equal the total level becomes $L_{1}+3\left(=L_{2}+3\right)$. If one source is dominant, the other source will have very little influence on the total level $\left(L_{1} \oplus L_{2} \approx L_{1}\right.$ if $\left.L_{1} \gg L_{2}\right)$.

As shown in Table 1, restricting the observations to include only properties with a total noise level of at least $55 \mathrm{~dB}$ leads to a reduction of the data set by two thirds compared to using all the observations with a total noise level of at least $50 \mathrm{~dB}$.

\section{Econometric model}

\subsection{Spatial dependence}

The first law of geography states "Everything is related to everything else, but near things are more related than distant things" (Tobler, 1970, p. 236). This statement has a bearing on hedonic regressions on 
property prices as the geographical location of a house is an important element of the good. The concept of near things being more related than distant things is named spatial dependence. Spatial dependence, or spatial autocorrelation, implies that the assumption of independence between observations is violated and is often handled through either a spatial lag or error model (Anselin, 1999, 2003). The different models can be hard to distinguish empirically, but they are based on different theoretical grounds. The decision between models in our study is based on diagnostic tests and in terms of fit.

Assuming a linear hedonic model, the spatial lag and error models are defined by (Kim et al., 2003),

$$
\begin{aligned}
& P=\rho W P+A \beta+\varepsilon, \\
& P=A \beta+\varepsilon \text { where } \varepsilon=\lambda W \varepsilon+u,
\end{aligned}
$$

and where $W$ is the spatial weight matrix that describes the correlation structure between observations. If $\rho$ and $\lambda$ are 0 the spatial lag and error models are reduced to the OLS model. The spatial dependence in the spatial error model in Eq. (5) is assumed to arise from a spatial pattern in omitted variables. Thus, it is appropriate when properties share common amenities that have a spatial pattern and these amenities cannot be controlled for. With the spatial error model the OLS estimator is unbiased but not efficient (Anselin, 1999).

The spatial lag model in Eq. (4) assumes that the property price (the dependent variable), in addition to its attributes, is affected by the prices of neighboring houses. This means that the total increase in property value due to a change in the attribute level can be decomposed into a direct and an indirect effect that occurs because, e.g., the increase in the value of the property in question raises the value of neighboring properties, whose increased value in turn raise the value of the property in question further. The reduced form of Eq. (4) shows the effect on the marginal benefit estimate from spatial lag dependence,

$$
P=[I-\rho W]^{-1} A \beta+\nu,
$$

where $\beta$ is a vector of the direct effect of the property's own characteristics, $[I-\rho W]^{-1}$ the indirect effect, and $\nu=[I-\rho W]^{-1} \varepsilon$. Hence, based on the spatial lag model the marginal implicit price for attribute $l$ is not given by $\beta_{l}$, but by $\beta_{l}[I-\rho W]^{-1}$ (Kim et al., 2003).

It is not evident, however, whether the indirect effect should be included when calculating the aggregated social benefit of a change in attribute level. The inclusion of the indirect effect depends on the mechanism behind the influence of neighboring properties (Small and Steimetz, 2007). Small and Steimetz (2007) refer to the externality that property values are affected by the values of neighboring houses as either technological or pecuniary. With a technological externality people obtain utility from living close to higher-priced houses; these houses may be better maintained or there may be a status effect. The 
indirect effect $\left([I-\rho W]^{-1}\right)$ then affects utility and therefore is important when estimating the marginal implicit price. Pecuniary externalities arise when the values of surrounding properties do not affect the utility of living in a specific property. A pecuniary effect arises, for instance, when buyers use the prices of surroundings properties as a guide to the value of their property of interest. With pecuniary externalities only the direct effect, estimated by $\beta_{l}$ in the spatial lag model, of an amenity change is part of welfare. Here the indirect effect is a transfer and, therefore, welfare neutral.

\subsection{Hedonic price functions}

The noise profiles of road noise and railway noise differ (Miedema and Oudshoorn, 2001), and it is therefore reasonable that the influence of road and railway noise on the property price varies. Since our data set contains information about noise levels from both road and railway noise for the properties, it enables us to estimate separately how the different noise sources affect the property prices. Thus, our regressions include separate variables for road and railway noise.

In estimating a relationship between noise and property prices, the choice of functional form is not self-evident. Economic theory leaves us without much guidance (Rosen, 1974) and a variety of forms is used in the empirical literature. The semi-logarithmic functional form, where the natural logarithm of the price is assumed to be a linear function of the noise level, is a common choice, but other functional forms such as piecewise linear regressions are also present in the literature (Theebe, 2004). We estimate: (i) a semi-logarithmic price function, since it is the model that dominates in the hedonic noise literature, and (ii) a function that is designed to have an increasing marginal WTP to reduce the noise level.

The semi-logarithmic model is given by,

$$
\ln \left(P_{i}\right)=\beta_{0}+\sum_{j=1}^{2} \beta_{j} L_{i j}^{\prime}+\sum_{h=1}^{H} \beta_{h+2} a_{i h}+\varepsilon_{i}
$$

where $L_{i j}^{\prime}$ denotes the noise variables, which are defined as the noise level above $45 \mathrm{~dB}$, subscript $i$ denotes single properties, $j$ denotes road (1) and rail (2) as above, and $a_{i h}$ other property attributes besides the noise variables. The semi-logarithmic model implies a convex relationship between the price of a property and the noise level (when $\beta_{j} \neq 0, j \in\{1,2\}$ ), i.e. the marginal WTP based on the price function is higher for low noise levels compared to the marginal WTP for high noise levels. However, if the marginal disutility of noise increases with the level, the marginal WTP should increase with the noise level. We, therefore, want to relax the assumption of a convex relationship and estimate a functional form that allows for a concave relationship between the property price and the noise level, i.e. a function where the marginal price discount is increasing with the noise level. 
A function that attempts to capture a concave relationship between the property price and the noise level is

$$
P_{i}=\gamma_{0} \prod_{j=1}^{2} f\left(L_{i j}^{\prime}\right) \prod_{h=1}^{H} a_{i h}^{\gamma_{h}}+\varepsilon_{i},
$$

where $\gamma_{h}$ are parameters to be estimated, and where

$$
f\left(L_{i j}^{\prime}\right)=1+\frac{1-b_{j}-\left(1-b_{j}\right) e^{k_{j} L_{i j}^{\prime}}}{e^{30 k_{j}}-1} .
$$

The parameter $b$ corresponds to the maximum effect at the highest allowable noise level $75 \mathrm{~dB}$ and $k$ describes the concavity of the function. Figure 2 (a) and (b) shows the functional form for different values of $b$ and $k$, holding the other parameter constant. The parameter $k$, restricted to be between 0 and 1 , is estimated as,

$$
k_{j}=\frac{e^{c_{j}}}{1+e^{c_{j}}},
$$

thus, $k$ is allowed to differ between road and rail noise. Hence, Eq. (8) makes it possible to assume not only different maximum effects from railway and road noise, but also different degrees of concavity for the two noise sources.

[Figure 2 about here.]

\section{Results}

\subsection{Spatial Dependence}

The semi-logarithmic model has been tested for spatial dependency using binary and row-standardized distance-based spatial weight matrices. The reason for not testing the concave function for spatial dependence is that methods for incorporating spatial dependence in non-linear regressions have not been developed. The test of spatial dependence was run on each subset, properties with a total noise level of at least 50 or $55 \mathrm{~dB}$ based on Eq. (3), and results are shown in Table 2.

The diagnostics in Table 2 are based on a row-standardized inverse distance weight matrix for the larger subset and a binary weight matrix for the smaller subset. The reason for using the binary weight matrix for the smaller subset is because we did not detect any spatial dependence with the matrices based on the inverse distance between properties for this subset. Several band widths were tested, including the largest Euclidian distance in our sample, and the chosen matrices are based on spatial diagnostics and goodness of fit. Based on Moran's I we can reject no spatial dependence, and based on the test statistics we conclude that the spatial lag model best describes our data.

[Table 2 about here] 


\subsection{Hedonic price regressions}

The regression results from the semi-logarithmic models for the two subsets are shown in Table 3. The spatial lag models reveal an improved fit and the spatial lag coefficients $(\rho)$ are statistically significant. We first focus on the the structural variables which are statistically significant and with the expected signs, with one exception, Linked, which is not statistically significant in the regression with only properties exposed to $L_{\text {tot }} \geq 55 \mathrm{~dB}$. Some of the neighborhood dummies are also significant compared to the reference group (Floda 2). The prices of properties situated within 150 meters from the motorway E20 are not significantly affected by the motorway, given that the noise level is controlled for. Distance to the nearest train station is not statistically significantly correlated with the property price in any regression, whereas distance to the entrance to the motorway has a positive significant coefficient in one OLS regression but is not statistically significant in the other regressions. Comparing the OLS with the spatial lag models we find that among statistically significant structural and geographical attributes the price effect is reduced in the spatial lag model for most variables. The exceptions are Living space which is unaffected, Quality index which is only affected in the smaller subset, and Terraced, Stenkullen1 and Stenkullen2 which have a stronger effect in the spatial lag model in the smaller subset.

[Table 3 about here.]

The coefficients for the noise variables are our main interest and for both subsets the discount for road noise is higher than for railway noise. We first focus on the OLS regression and using the observations with a total noise level equal to or above $50 \mathrm{~dB}$, the road noise coefficient is highly significant, whereas the railway noise coefficient is significant only on the $10 \%$ level. The coefficients imply that a $1 \mathrm{~dB}$ increase in road and railway noise is associated with approximately a $1.2 \%$ and a $0.4 \%$ decrease in property price. Using only the properties with a total noise level equal to or above $55 \mathrm{~dB}$ reveals a slightly higher influence of both road and railway noise on the price, $1.7 \%$ for road noise and $0.7 \%$ for railway noise per $\mathrm{dB}$, both highly significant. The coefficients for road and railway noise are statistically significantly different in both regressions. The fit is slightly better using the data set with only properties with a total noise level equal to or above $55 \mathrm{~dB}$ with a $R^{2}$ at 0.56 , compared to using properties where the threshold is set to $50 \mathrm{~dB}$ with a $R^{2}$ at 0.51 .

The spatial lag model for the sample with a total noise level equal to or above $50 \mathrm{~dB}$ shows that there is no change in the direct effect on the price from the road noise, and the coefficient estimate of Rail noise is only marginally effected, it changes from -0.004 to -0.003 . The coefficient for the railway noise variable is, however, less significant. It is significant at a $10 \%$ one-tailed test level $(p-v a l=0.104)$. In the subset with a total noise level equal to or above $55 \mathrm{~dB}$ the spatial lag model has no effect on 
the coefficient estimates of Road noise and Rail noise. Hence, if the spatial externality is assumed to be pecuniary the implicit price from the OLS and the direct effect estimated by the spatial lag model are of the same magnitude. However, if the externality is assumed to be technological the marginal implicit price would need to be adjusted with the indirect effect. ${ }^{4}$ Since we have no information to determine whether the spatial dependence is pecuniary or technological, and since the direct effect is similar between the OLS and spatial lag model, we choose the conservative approach and assume that the effect is indeed pecuniary.

The concave price function is estimated using nonlinear least-square estimation. This function is only estimated for the larger subset due to problem of convergence when the smaller subset was used. This functional form reveals similar results to the semi-logarithmic functional form in terms of signs and statistical significance of the coefficient estimates. Regarding the noise variables, the relevant hypothesis testing for $b_{j}$ is whether the coefficient is equal to one, since $b_{j}=1$ suggests that the price is not influenced by the noise level. We find that $b_{1}$ (road noise) is significantly different from 1 while $b_{2}$ (rail noise) is not significantly different from 1 at the $10 \%$ level. The $k$-parameter is calculated using the estimates of $c_{j}$ (see Eq. (10)), and is restricted to being between 0 and 1 where a higher value implies a more concave function and a value close to zero implies an almost linear relationship between the noise level and the property price.

[Table 4 about here.]

The results show that the relationship between property value and rail noise is more concave than the relationship between property value and road noise. This is illustrated in Figure 3, where the factors $e^{\beta_{j} L_{i j}^{\prime}}$ and $f\left(L_{i j}^{\prime}\right)$ from the semi-logarithmic (Eq. (7)) and concave model (Eq. (8)), respectively, are plotted with the estimated parameters. The semi-logarithmic model estimates a stronger negative effect on the price at low noise levels compared to the concave model, and the effect is reversed at high noise levels.

[Figure 3 about here.]

The Noise Sensitivity Depreciation Index (NSDI) is often used to compare results from SP and RP noise studies (Bateman et al., 2001; Navrud, 2004). It gives the percentage change in property value due to a $1 \mathrm{~dB}$ decrease in noise exposure,

$$
\mathrm{NSDI}=\left|\frac{\partial P}{\partial L} \frac{100}{P}\right|
$$

4 The indirect effect, the spatial multiplier, is $(1-\rho)^{-1}$ and $[I-\rho W]^{-1}$ for a lag model with a row-standardized and binary weight matrix, respectively (Kim et al., 2003) 
The semi-logarithmic functional form has the advantage of giving an easily interpretable noise coefficient that can be approximately interpreted directly as the NSDI. This means that the NSDI is constant for all noise levels.

For the concave price function the NSDI is given by,

$$
\operatorname{NSDI}\left(L_{i j}^{\prime}\right)=100 \cdot \frac{f^{\prime}\left(L_{i j}^{\prime}\right)}{f\left(L_{i j}^{\prime}\right)}=100 \cdot \frac{k_{j}\left(1-b_{j}\right) e^{k_{j} L_{i j}^{\prime}}}{e^{30 k_{j}}-b_{j}-\left(1-b_{j}\right) e^{k_{j} L_{i j}^{\prime}}}
$$

which, since other attributes cancel, only depends on the noise level. ${ }^{5}$ Thus, the NSDI of the concave model increases with the noise level as a consequence of the functional form.

Table 5 shows NSDI estimates for the semi-logarithmic models and for different noise levels for the concave model. The higher degree of concavity for rail noise leads to lower NSDI values from rail noise than road noise for low noise levels but higher values for very high noise levels. The effect of rail noise on the property prices is lower than the effect of road noise for all noise levels except the highest (70 dB). There are few properties with noise levels above $70 \mathrm{~dB}$, only three properties with road noise at $70 \mathrm{~dB}$ or above and three properties with railway noise above $70 \mathrm{~dB}$. This means that the calculated NSDI are based on very few observations for the highest noise levels. Comparing the NSDI for road noise from the semi-logarithmic model with that from the concave model shows that it is lower for all noise levels for the semi-logarithmic model compared with the concave model. The NSDI for railway noise shows more mixed results where the concave model gives lower price discounts for railway noise at low noise levels, but higher discounts at higher noise levels compared to the semi-logarithmic model.

[Table 5 about here.]

\section{Discussion}

This study estimates the effect of exposure to road and railway noise on property prices. We have also examined the effect of different functional forms and of the assumption when noise has an effect on the property price $(50$ or $55 \mathrm{~dB}$ ). In contrast to the findings in Day et al. (2007) we show that road noise has a larger impact on property prices than railway noise. ${ }^{6}$ Our results are in line with the evidence from the acoustical literature that individuals are more disturbed by road than railway noise (Miedema and Oudshoorn, 2001).

We detect spatial dependency in our sample. The coefficient estimates of our variables of major concern, road and railway noise, are not or only marginally affected by the use of spatial lag models

${ }^{5} f^{\prime}\left(L_{i j}^{\prime}\right)=-\frac{k(1-b) e^{k L_{i j}^{\prime}}}{e^{30 k}-1}$

${ }^{6}$ Except at the highest noise levels $(\geq 70 \mathrm{~dB})$ using the concave price function. Note that the estimated price functions at these high noise levels are based on a small number of observations. 
compared to OLS. Moreover, the findings between price functions and subsets are robust with expected signs of statistically significant coefficient estimates. Moreover, we show that the chosen threshold level ( 50 or $55 \mathrm{~dB}$ ) has an impact on the results. In the semi-logarithmic function the influence of the noise is higher for the $55 \mathrm{~dB}$ threshold level for both noise sources.

Our estimates of NSDI for road noise in the semi-logarithmic price function are within the range of previous estimates, e.g. Bateman et al. (2004) reported a range of 0.08-2.22 with a mean value of 0.55. The estimates from the concave function are within the range for noise levels 55,60 , and $65 \mathrm{~dB}$, but above the range for $70 \mathrm{~dB}$, which is true for both noise sources. Overall, we conclude that our NSDI estimates are higher than most of the values reported in Bateman et al. (2004). For railway noise the number of empirical estimates of NSDI is limited; however, Day et al. (2007) report a NSDI of 0.67. Our estimate from the semi-logarithmic model and a total noise level above or equal to $55 \mathrm{~dB}$ is close to this estimate, $0.70-0.72$, whereas the estimate from the other subsample is lower and the estimates from the concave function varies between $0.08-4.09$.

A question not addressed in this study is what noise indicator to use. We use the equivalent level for a full 24-hour period, $L_{\mathrm{AEq}, 24 \mathrm{~h}}$, which is the most commonly used noise indicator. An example of another indicator that better reflects both general annoyance and sleep disturbance is the $L_{\text {den }}$ (level day evening night), which has been chosen as the noise indicator in the Environmental Noise Directive (European Commission, 2002). Baranzini and Ramirez (2005) examined the effect of different noise indicators in hedonic studies and found that the impact was "fundamentally the same, whatever the noise measure used" (p. 643). The above mentioned and examined noise indicators are all scientific indicators. Individuals are, however, assumed to base their decisions on subjective beliefs. Thus, hedonic studies should then be based on subjective and not scientific noise indicators. Baranzini et al. (2008) studied how estimates differed between using a subjective and a scientific noise indicator and found that for moderate and high noise levels (55 to $75 \mathrm{~dB}$ ) the scientific noise measure approximated the subjective measure, and that the subjective measure did not improve the hedonic estimation.

A theoretically consistent measure of welfare estimates for non-marginal changes of the noise levels requires the estimation of the second step of Rosen's hedonic regression technique (Rosen, 1974; Freeman, 1974). Only the first step is estimated in this study, which means that theoretically consistent estimates for non-marginal changes cannot be obtained from our results. However, if the price function does not shift as a result of changes in the noise level, e.g. if the number of properties with a change is small relative to the total market, the price function may be used to calculate the welfare measure (Freeman, 2003, p. 379). The official Swedish policy values for noise abatement (SIKA, 2008) are based on estimates from a hedonic study on road traffic noise using this approach (Wilhelmsson, 2000). The values show 
a highly convex relationship between the social cost of noise exposure and the noise level, which is a result of the functional form of the price equation in Wilhelmsson (2000). Our study reveals a less convex relationship for road noise, which is in line with Day et al. (2007), who estimated the second step, and thus, a theoretically consistent welfare estimate.

Our findings, which contrast with Day et al. (2007) but are in line with the evidence from the acoustical literature (Miedema and Oudshoorn, 2001), are especially interesting since respondents from the study on which the data set is based stated that they were more annoyed by railway than road noise (Öhrström et al., 2005). Öhrström et al. (2005) assumed that this was an effect of strategic answers by the respondents, since a new railway track through Lerum was being planned at the time of the survey. The conflicting evidence of stated and revealed preferences for road and railway noise is interesting and highlights the importance of further research.

\section{References}

Andersson, H.: 2008, 'Willingness to Pay for Car Safety: Evidence from Sweden'. Environmental and Resource Economics 41(4), 579-594.

Andersson, H. and M. Ögren: 2007a, 'Noise Charges in Rail Infrastructure: A Pricing Schedule Based on the Marginal Cost Principle'. Transport Policy 14(3), 204-213.

Andersson, H. and M. Ögren: 2007b, 'Noise Charges in Road Traffic: A Pricing Schedule Based on the Marginal Cost Principle'. Working Paper 2007:15, VTI, Dept. of Transport Economics, Stockholm, Sweden.

Anselin, L.: 1999, 'Spatial Econometrics'. Mimeo, University of Texas at Dallas, USA.

Anselin, L.: 2003, 'Spatial Externalities, Spatial Multipliers, and Spatial Econometrics'. International Regional Science Review 26(2), 153-166.

Arsenio, E., A. L. Bristow, and M. Wardman: 2006, 'Stated choice valuations of traffic related noise'. Transportation Research Part D: Transport and Environment 11(1), 15-31.

Baranzini, A. and J. V. Ramirez: 2005, 'Paying for Quiteness: The Impact of Noise on Geneva Rents'. Urban Studies 42(4), 633-646.

Baranzini, A., C. Schaerer, J. V. Ramirez, and P. Thalmann: 2008, 'Feel it or Measure it. Percieved vs. Measured Noise in Hedonic Models'. EAERE 16th Annual Conference.

Bateman, I., B. Day, I. Lake, and A. Lovett: 2001, 'The Effects of Road Traffic on Residential Property Values: A Literature Review and Hedonic Pricing Study'. Technical report, University of East Anglia, Economic \& Social Research Council, and Univeristy College London. 
Bateman, I. J., B. H. Day, and L. Iain: 2004, 'The Valuation of Transport-Related Noise in Birmingham'. Non-technical report to DfT, University of East Anglia, UK.

Day, B., I. Bateman, and I. Lake: 2007, 'Beyond Implicit Prices: Recovering Theoretically Consistent and Transferable Values for Noise Avoidance from a Hedonic Property Price Model'. Environmental and Resource Economics 37(1), 211-232.

Ekeland, I., J. J. Heckman, and L. Nesheim: 2004, 'Identification and Estimation of Hedonic Models'. Journal of Political Economy 112(1), 60-109.

European Commission: 1996, 'Future Noise Policy - European Commission Green Paper'. Report COM(96) 540 final, European Commission, Brussels, Belgium.

European Commission: 1998, 'White Paper on Fair Pricing for Transport Infrastructure Use'.

European Commission: 2002, 'Environmental noise directive 2002/49/EG'.

Freeman, A. M.: 1974, 'Air Pollution and Property Values: A Further Comment'. Review of Economics and Statistics 56, 554-556.

Freeman, A. M.: 2003, The Measurement of Environmental and Resource Values. Washington, D.C., US: Resources for the Future, 2 edition.

Garrod, G. D., R. Scarpa, and K. G. Willis: 2002, 'Estimating the Benefits of Traffic Calming on Through Routes'. Journal of Transport Economics and Policy 36(2), 211-231.

Haab, T. C. and K. E. McDonnel: 2003, Valuing Environmental and Natural Resources: The Econometrics of Non-Market Valuation. Cheltenham, UK: Edward Elgar.

Jonasson, H. and H. Nielsen: 1996, 'Road Traffic Noise - Nordic Prediction Method'. TemaNord 1996:525, Nordic Council of Ministers, Copenhagen, Denmark. ISBN 92-9120-836-1.

Kim, C. W., T. T. Phipps, and L. Anselin: 2003, 'Measuring the benefits of air quality improvement: a spatial hedonic approach'. Journal of Environmental Economics and Management 45.

Miedema, H. M. E. and C. G. M. Oudshoorn: 2001, 'Annoyance from Transportation Noise: Relationships with Exposure Metrics DNL and DENL and Their Confidence Intervals'. Environmental Health Perspectives 109(4), 409-416.

Navrud, S.: 2004, 'The Economic Value of Noise Within the European Union - A Review and Analysis of Studies'. Mimeo.

Nelson, J. P.: 1982, 'Highway Noise and Property Values: A Survey of Recent Evidence'. Journal of Transport Economics and Policy 16(2), 117-138.

Nelson, J. P.: 2004, 'Meta-Analysis of Airport Noise and Hedonic Property Values'. Journal of Transport Economics and Policy 38(1), 1-28. 
Nielsen, H.: 1996, 'Railway Traffic Noise - the Nordic Prediction Method'. TemaNord 1996:524, Nordic Council of Ministers, Copenhagen, Denmark. ISBN 92-9120-837-X.

Nijland, H. A., E. E. M. M. Van Kempen, G. P. Van Wee, and J. Jabben: 2003, 'Costs and Benefits of Noise Abatement Measures'. Transport Policy 10(2), 131-140.

Nijland, H. A. and G. P. Van Wee: 2005, 'Traffic Noise in Europe: A Comparison of Calculation Methods, Noise Indices and Noise Standards for Road and Railroad Traffic in Europe'. Transport Reviews 25(5), 591-612.

Öhrström, E., A. Skånberg, L. Barreård, H. Svensson, and P. Ängerheim: 2005, 'Effects of Simultaneous Exposure to Noise from Road and Railway Traffic'. Inter-Noise.

Palmquist, R. B.: 2005, Handbook of Environmental Economics: Valuing Environmental Changes, Vol. 2 of Handbooks in Economics 20, Chapt. Property Value Models, pp. 763-819. Amsterdam, The Netherlands: North-Holland.

Rosen, S.: 1974, 'Hedonic Prices and Implicit Markets: Product Differentiation in Pure Competition'. Journal of Political Economy 82(1), 34-55.

Sandberg, U. and J. A. Ejsmont: 2002, Tyre/Road Noise Reference Book. Kisa, Sweden: Informex. ISBN 91-631-2610-9.

SIKA: 2008, 'Samhällsekonomiska kalkylprinciper och kalkylvärden för transportsektorn'. SIKA PM 2008:3, SIKA (Swedish Institute for Transport and Communications Analysis), Stockholm, Sweden.

Small, K. A. and S. Steimetz: 2007, 'Spatial Hedonics and the Willingness to Pay for Residential Amenities'. Working Papers 05-06-31, University of California-Irvine, Department of Economics.

Theebe, M. A. J.: 2004, 'Planes, Trains and Automobiles: The Impact of Traffic Noise on House Prices'. Journal of Real Estate Finance and Economics 28(2/3), 209-234.

Tobler, W.: 1970, 'A Computer Movie Simulating Urban Growth in the Detroit Region'. Economic Geography 46, 234-240.

Wilhelmsson, M.: 2000, 'The Impact of Traffic Noise on the Values of Single-family Houses'. Journal of Environmental Planning and Management 43(6), 799-815. 
Figure 1 Sketched map over the research area

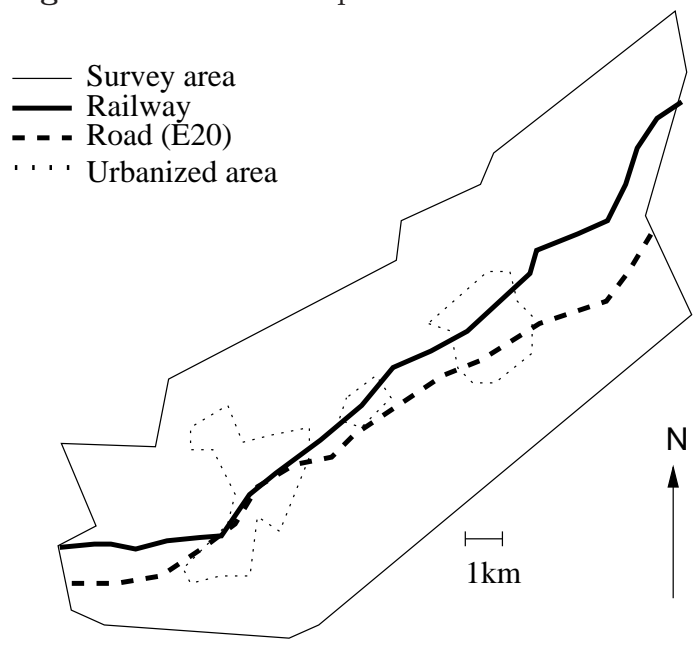

Figure 2 Influence of the parameters $b$ and $k$ on the price function (9)

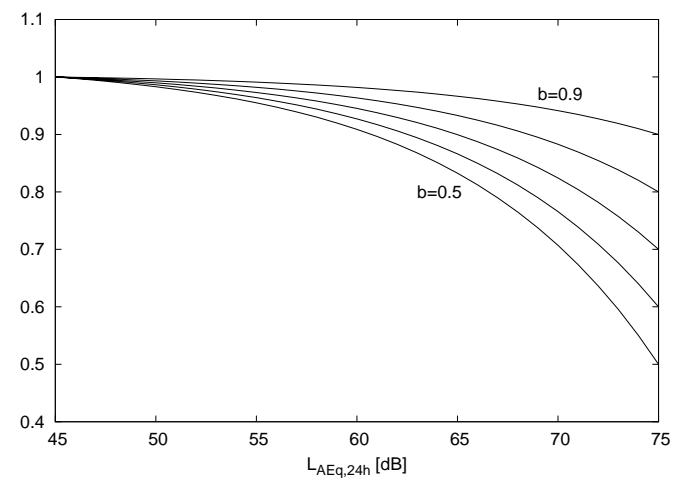

(a)

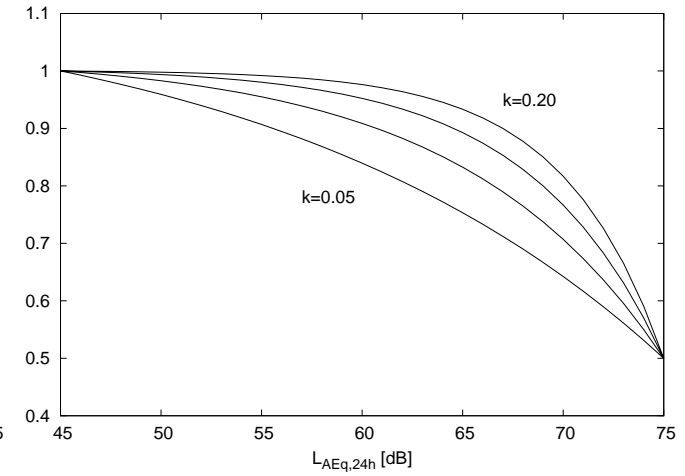

(b) 
Figure 3 Estimated price functions for the semi-logarithmic and concave functions for road and railway noise $\left(L_{\text {tot }} \geq 50 \mathrm{~dB}\right)$

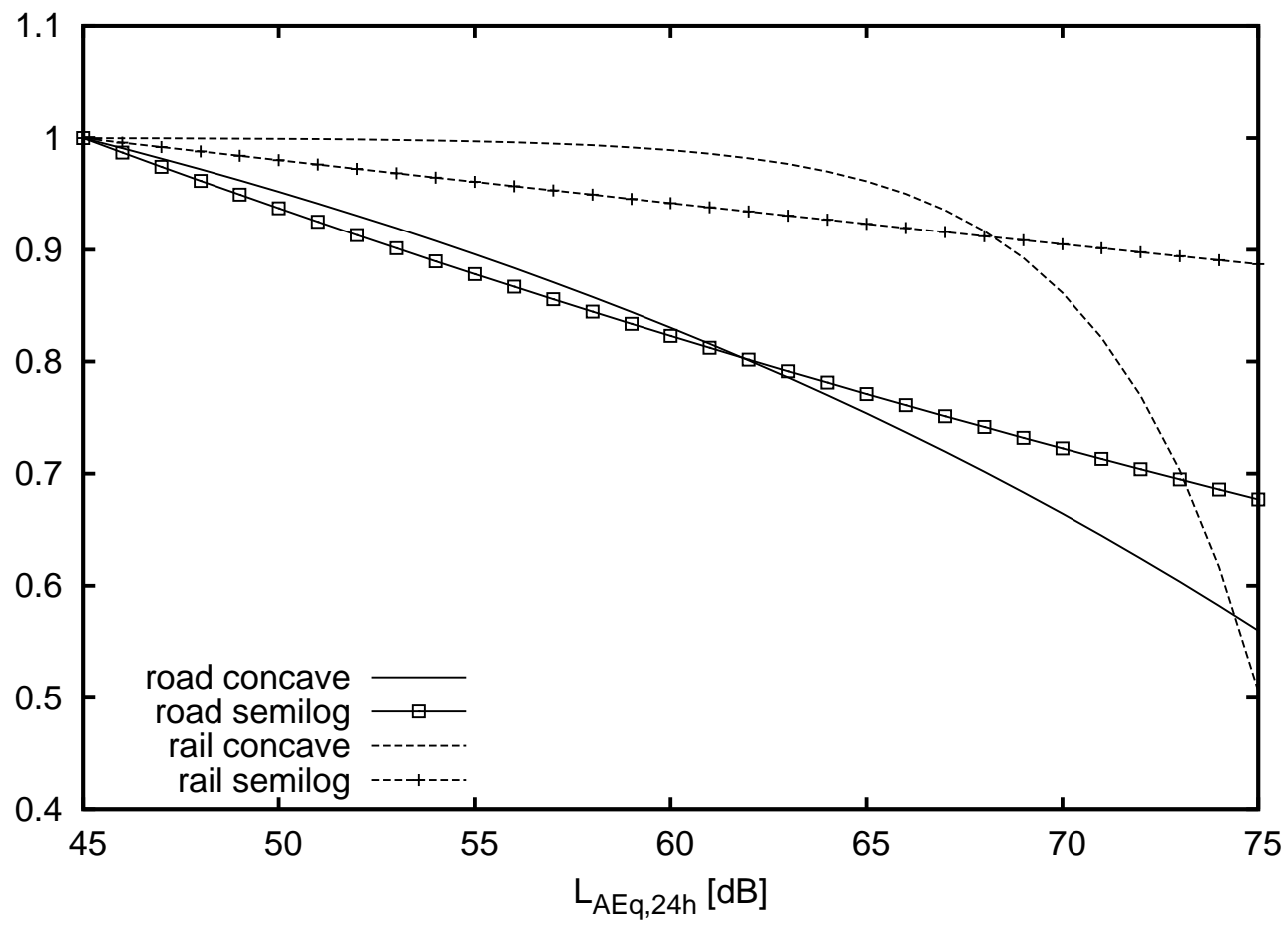


Table 1 Descriptive statistics

\begin{tabular}{|c|c|c|c|c|}
\hline \multirow[b]{2}{*}{ Variable } & \multirow[b]{2}{*}{ Description } & \multicolumn{3}{|c|}{ Mean value } \\
\hline & & All & $L_{\text {tot }} \geq 50 \mathrm{~dB}$ & $L_{\text {tot }} \geq 55 \mathrm{~dB}$ \\
\hline Price & $\begin{array}{l}\text { Property price in thousand SEK and } 2004 \\
\text { price level }\end{array}$ & $\begin{array}{l}1887.215 \\
(655.354)\end{array}$ & $\begin{array}{l}1917.913 \\
(675.549)\end{array}$ & $\begin{array}{l}1812.621 \\
(738.747)\end{array}$ \\
\hline Living space & Living space in square meters & $\begin{array}{l}128.709 \\
(48.099)\end{array}$ & $\begin{array}{l}130.144 \\
(47.606)\end{array}$ & $\begin{array}{l}132.350 \\
(61.515)\end{array}$ \\
\hline Quality Index & Index of indoor-quality & $\begin{array}{l}28.934 \\
(5.359)\end{array}$ & $\begin{array}{l}29.016 \\
(5.517)\end{array}$ & $\begin{array}{l}28.299 \\
(5.444)\end{array}$ \\
\hline Dist. station & Distance to nearest railway station in $\mathrm{km}$ & $\begin{array}{c}1.792 \\
(1.222)\end{array}$ & $\begin{array}{c}1.672 \\
(1.320)\end{array}$ & $\begin{array}{l}1.585 \\
(1.591)\end{array}$ \\
\hline Dist. entrance & Distance to nearest motorway entrance in $\mathrm{km}$ & $\begin{array}{c}2.084 \\
(1.033)\end{array}$ & $\begin{array}{l}1.960 \\
(1.005)\end{array}$ & $\begin{array}{l}1.802 \\
(0.950)\end{array}$ \\
\hline Road noise & Road noise in $\mathrm{dB}$ exceeding $45 \mathrm{~dB}$ & $\begin{array}{c}5.065 \\
(4.535)\end{array}$ & $\begin{array}{l}7.566 \\
(4.17)\end{array}$ & $\begin{array}{l}11.415 \\
(4.895)\end{array}$ \\
\hline Rail noise & Rail noise in $\mathrm{dB}$ exceeding $45 \mathrm{~dB}$ & $\begin{array}{l}1.837 \\
(4.040)\end{array}$ & $\begin{array}{c}3.005 \\
(4.888)\end{array}$ & $\begin{array}{c}6.680 \\
(6.597)\end{array}$ \\
\hline Terraced & Dummy equals one if terraced house & 0.056 & 0.063 & 0.081 \\
\hline Linked & - " - if house linked by a garage & 0.100 & 0.093 & 0.051 \\
\hline Detached & - " - if detached house & 0.843 & 0.844 & 0.868 \\
\hline Aspen 1 & - " - if $<1 \mathrm{~km}$ from nearest stn Aspen & 0.017 & 0.026 & 0.048 \\
\hline Aspen 2 & - " - if 1-2 km from nearest stn Aspen & 0.054 & 0.043 & 0.015 \\
\hline Aspedalen1 & - " - if $<1 \mathrm{~km}$ from nearest stn Aspedalen & 0.033 & 0.049 & 0.102 \\
\hline Aspedalen2 & - " - if 1-2 km from nearest stn Aspedalen & 0.096 & 0.088 & 0.039 \\
\hline Lerum1 & - " - if $<1 \mathrm{~km}$ from nearest stn Lerum & 0.040 & 0.063 & 0.117 \\
\hline Lerum2 & - " - if $1-2 \mathrm{~km}$ from nearest stn Lerum & 0.230 & 0.252 & 0.177 \\
\hline Floda1 & - " - if $<1 \mathrm{~km}$ from nearest stn Floda & 0.023 & 0.035 & 0.042 \\
\hline Floda2 & - " - if 1-2 km from nearest stn Floda & 0.299 & 0.246 & 0.180 \\
\hline Stenkullen1 & - " - if $<1 \mathrm{~km}$ from nearest stn Stenkullen & 0.013 & 0.019 & 0.045 \\
\hline Stenkullen2 & - " - if 1-2 km from nearest stn Stenkullen & 0.047 & 0.067 & 0.153 \\
\hline Countryside & - " - if $>2 \mathrm{~km}$ from nearest station & 0.149 & 0.112 & 0.084 \\
\hline E20 150m & - " - if within $150 \mathrm{~m}$ from motorway & 0.082 & 0.136 & 0.347 \\
\hline $\mathbf{N}$ & & 1738 & 1034 & 334 \\
\hline
\end{tabular}

Standard deviations in brackets. For dummies, std.dev. $(x)=\sqrt{\bar{x}(1-\bar{x})}$.

EUR 1 = SEK 9.13, www.riksbank.se, 9/16/2008

Table 2 Diagnostic tests for spatial dependency in OLS regression

\begin{tabular}{|c|c|c|c|c|c|c|}
\hline \multirow[b]{2}{*}{ Test } & \multicolumn{3}{|c|}{$L_{\text {tot }} \geq 50 \mathrm{~dB}$} & \multicolumn{3}{|c|}{$L_{\text {tot }} \geq 55 \mathrm{~dB}$} \\
\hline & Statistic & $\mathrm{df}$ & p-value & Statistic & $\mathrm{df}$ & $\mathrm{p}$-value \\
\hline \multicolumn{7}{|l|}{ Spatial error: } \\
\hline Moran's I & 2.502 & 1 & 0.012 & 5.224 & 1 & 0.000 \\
\hline Lagrange multiplier & 0.469 & 1 & 0.494 & 0.271 & 1 & 0.603 \\
\hline Robust Lagrange multiplier & 8.104 & 1 & 0.004 & 0.456 & 1 & 0.500 \\
\hline \multicolumn{7}{|l|}{ Spatial lag: } \\
\hline Lagrange multiplier & 14.700 & 1 & 0.000 & 11.055 & 1 & 0.001 \\
\hline Robust Lagrange multiplier & 22.335 & 1 & 0.000 & 11.240 & 1 & 0.001 \\
\hline Weight matrix & \multicolumn{3}{|c|}{$\begin{array}{l}\text { Inverse distance } \\
\text { Critical distance } 10 \mathrm{~km} \\
\text { Row-standardized }\end{array}$} & \multicolumn{3}{|c|}{$\begin{array}{l}\text { Binary } \\
\text { Critical distance } 4 \mathrm{~km} \\
\text { Not row-standardized }\end{array}$} \\
\hline
\end{tabular}


Table 3 Regression results semi-logarithmic function

\begin{tabular}{|c|c|c|c|c|}
\hline \multirow[b]{2}{*}{ Variable } & \multicolumn{2}{|c|}{$L_{\text {tot }} \geq 50 \mathrm{~dB}$} & \multicolumn{2}{|c|}{$L_{\text {tot }} \geq 55 \mathrm{~dB}$} \\
\hline & OLS & Spatial lag & OLS & Spatial lag \\
\hline Living space & $\begin{array}{c}0.003^{* * *} \\
(0.001)\end{array}$ & $\begin{array}{c}0.003^{* * *} \\
(0.001)\end{array}$ & $\begin{array}{c}0.003^{* * *} \\
(0.001)\end{array}$ & $\begin{array}{c}0.003^{* * *} \\
(0.001)\end{array}$ \\
\hline Quality index & $\begin{array}{c}0.014^{* * *} \\
(0.003)\end{array}$ & $\begin{array}{c}0.014^{* * *} \\
(0.003)\end{array}$ & $\begin{array}{c}0.018^{* * *} \\
(0.004)\end{array}$ & $\begin{array}{c}0.017^{* * *} \\
(0.004)\end{array}$ \\
\hline Terraced & $\begin{array}{c}-0.270^{* * *} \\
(0.024)\end{array}$ & $\begin{array}{c}-0.239^{* * *} \\
(0.026)\end{array}$ & $\begin{array}{c}-0.239^{* * *} \\
(0.040)\end{array}$ & $\begin{array}{c}-0.252^{* * *} \\
(0.039)\end{array}$ \\
\hline Linked & $\begin{array}{c}-0.163^{* * *} \\
(0.020)\end{array}$ & $\begin{array}{c}-0.134^{* * *} \\
(0.023)\end{array}$ & $\begin{array}{c}0.002 \\
(0.059)\end{array}$ & $\begin{array}{c}0.004 \\
(0.057)\end{array}$ \\
\hline Aspen1 & $\begin{array}{c}0.272^{* * *} \\
(0.053)\end{array}$ & $\begin{array}{c}0.184^{* * *} \\
(0.063)\end{array}$ & $\begin{array}{c}0.274^{* * * *} \\
(0.085)\end{array}$ & $\begin{array}{c}0.191^{* *} \\
(0.085)\end{array}$ \\
\hline Aspen2 & $\begin{array}{c}0.175^{* * *} \\
(0.038)\end{array}$ & $\begin{array}{c}0.099 * * \\
(0.050)\end{array}$ & $\begin{array}{c}0.170 \\
(0.137)\end{array}$ & $\begin{array}{c}0.127 \\
(0.099)\end{array}$ \\
\hline Aspedalen1 & $\begin{array}{c}0.257^{* * *} \\
(0.048)\end{array}$ & $\begin{array}{c}0.173^{* * *} \\
(0.055)\end{array}$ & $\begin{array}{c}0.223^{* * *} \\
(0.080)\end{array}$ & $\begin{array}{c}0.018 \\
(0.090)\end{array}$ \\
\hline Aspedalen2 & $\begin{array}{c}0.318^{* * *} \\
(0.031)\end{array}$ & $\begin{array}{c}0.235 * * * \\
(0.045)\end{array}$ & $\begin{array}{c}0.395^{* * *} \\
(0.063)\end{array}$ & $\begin{array}{c}0.174^{* *} \\
(0.078)\end{array}$ \\
\hline Lerum1 & $\begin{array}{c}0.240^{* * *} \\
(0.039)\end{array}$ & $\begin{array}{c}0.166^{* * *} \\
(0.045)\end{array}$ & $\begin{array}{c}0.282^{* * * *} \\
(0.061)\end{array}$ & $\begin{array}{l}-0.013 \\
(0.091)\end{array}$ \\
\hline Lerum2 & $\begin{array}{c}0.169 * * * \\
(0.022)\end{array}$ & $\begin{array}{c}0.121^{* * *} \\
(0.028)\end{array}$ & $\begin{array}{c}0.183^{* * *} \\
(0.052)\end{array}$ & $\begin{array}{l}-0.144 \\
(0.102)\end{array}$ \\
\hline Country side & $\begin{array}{c}0.002 \\
(0.052)\end{array}$ & $\begin{array}{l}-0.016 \\
(0.054)\end{array}$ & $\begin{array}{c}-0.236^{* *} \\
(0.114)\end{array}$ & $\begin{array}{c}-0.120 \\
(0.110)\end{array}$ \\
\hline Stenkullen1 & $\begin{array}{c}0.008 \\
(0.076)\end{array}$ & $\begin{array}{c}0.026 \\
(0.076)\end{array}$ & $\begin{array}{c}0.073 \\
(0.107)\end{array}$ & $\begin{array}{c}-0.219^{* *} \\
(0.111)\end{array}$ \\
\hline Stenkullen2 & $\begin{array}{l}-0.060 \\
(0.052)\end{array}$ & $\begin{array}{l}-0.050 \\
(0.051)\end{array}$ & $\begin{array}{c}-0.153^{* * *} \\
(0.059)\end{array}$ & $\begin{array}{c}-0.439 * * * \\
(0.102)\end{array}$ \\
\hline Floda1 & $\begin{array}{c}0.065 \\
(0.049)\end{array}$ & $\begin{array}{c}0.064 \\
(0.050)\end{array}$ & $\begin{array}{c}0.156 \\
(0.097)\end{array}$ & $\begin{array}{c}0.146 \\
(0.094)\end{array}$ \\
\hline E20 150m & $\begin{array}{c}-0.031 \\
(0.030)\end{array}$ & $\begin{array}{l}-0.031 \\
(0.029)\end{array}$ & $\begin{array}{c}0.009 \\
(0.043)\end{array}$ & $\begin{array}{l}8 \cdot 10^{-5} \\
(0.040)\end{array}$ \\
\hline Dist. station & $\begin{array}{c}-0.007 \\
(0.017)\end{array}$ & $\begin{array}{c}0.004 \\
(0.019)\end{array}$ & $\begin{array}{c}0.015 \\
(0.026)\end{array}$ & $\begin{array}{c}0.037 \\
(0.028)\end{array}$ \\
\hline Dist. entrance & $\begin{array}{c}0.031^{* *} \\
(0.014)\end{array}$ & $\begin{array}{c}0.014 \\
(0.016)\end{array}$ & $\begin{array}{c}0.030 \\
(0.032)\end{array}$ & $\begin{array}{l}0.051^{*} \\
(0.030)\end{array}$ \\
\hline Road noise & $\begin{array}{c}-0.012^{* * *} \\
(0.003)\end{array}$ & $\begin{array}{c}-0.012^{* * *} \\
(0.003)\end{array}$ & $\begin{array}{c}-0.017 * * * \\
(0.004)\end{array}$ & $\begin{array}{c}-0.017^{* * *} \\
(0.004)\end{array}$ \\
\hline Rail noise & $\begin{array}{c}-0.004^{*} \\
(0.002)\end{array}$ & $\begin{array}{c}-0.003 \\
(0.002)\end{array}$ & $\begin{array}{c}-0.007^{* * *} \\
(0.003)\end{array}$ & $\begin{array}{c}-0.007^{* * *} \\
(0.002)\end{array}$ \\
\hline Constant & $\begin{array}{c}6.688^{* * *} \\
(0.086)\end{array}$ & $\begin{array}{l}2.864^{*} \\
(1.607)\end{array}$ & $\begin{array}{c}6.662^{* * *} * \\
(0.141)\end{array}$ & $\begin{array}{c}6.213^{* * *} \\
(0.174)\end{array}$ \\
\hline$\rho$ & & $\begin{array}{c}0.517^{* *} \\
(0.217)\end{array}$ & & $\begin{array}{c}5 \cdot 10^{-4 * * *} \\
\left(1 \cdot 10^{-4}\right)\end{array}$ \\
\hline $\bar{N}$ & 1034 & 1034 & 334 & 334 \\
\hline$R^{2}$ & 0.508 & 0.512 & 0.561 & 0.575 \\
\hline Log likelihood & -12.973 & -7.942 & -21.252 & -15.663 \\
\hline
\end{tabular}

Robust standard errors in brackets.

Significance levels: ${ }^{*} 10 \%, * * 5 \%, * * * 1 \%$ 
Table 4 Regression results concave function $\left(L_{\mathrm{tot}} \geq 50 \mathrm{~dB}\right)$

\begin{tabular}{lcc}
\hline \multicolumn{1}{c}{ Variable } & Coefficient & (Std. Err.) \\
\hline Living space & $0.485^{* * *}$ & $(0.049)$ \\
Quality index & $0.310^{* * *}$ & $(0.062)$ \\
Terraced & $-0.315^{* * *}$ & $(0.025)$ \\
Linked & $-0.174^{* * *}$ & $(0.026)$ \\
Aspen1 & $0.274^{* * *}$ & $(0.058)$ \\
Aspen2 & $0.218^{* * *}$ & $(0.055)$ \\
Aspedalen1 & $0.219^{* * *}$ & $(0.051)$ \\
Aspedalen2 & $0.312^{* * *}$ & $(0.029)$ \\
Lerum1 & $0.187^{* * *}$ & $(0.038)$ \\
Lerum2 & $0.153^{* * *}$ & $(0.027)$ \\
Country side & 0.063 & $(0.044)$ \\
Stenkullen1 & 0.079 & $(0.100)$ \\
Stenkullen2 & -0.012 & $(0.079)$ \\
Floda1 & 0.080 & $(0.057)$ \\
E20 150m & -0.012 & $(0.034)$ \\
Dist. station & -0.004 & $(0.029)$ \\
Dist. entrance & 0.039 & $(0.029)$ \\
$b_{1}$ & $0.560^{* * *}$ & $(0.117)$ \\
$c_{1}$ & $-3.448^{* *}$ & $(1.396)$ \\
$b_{2}$ & 0.506 & $(0.712)$ \\
$c_{2}$ & -1.078 & $(2.094)$ \\
Constant & $62.848^{* * *}$ & $(14.536)$ \\
\hline$k_{1}$ & 0.031 & $(0.417)$ \\
$k_{2}$ & 0.254 & $(0.397)$ \\
\hline $\mathrm{N}$ & & 1034 \\
$\mathrm{R}^{2}$ & & \\
\hline Robust standar & & \\
\hline
\end{tabular}

Robust standard errors in brackets.

Significance levels: * $10 \%, * * 5 \%, * * * 1 \%$

Subscript $j=\{1,2\}$ denotes road (1) and rail (2). $k_{j}=e^{c_{j}} /\left(1+e^{c_{j}}\right)$

Table 5 Noise sensitivity depreciation index (NSDI)

\begin{tabular}{lccccc}
\hline & \multicolumn{2}{c}{$L_{\text {tot }} \geq 50 \mathrm{~dB}$} & & \multicolumn{2}{c}{$L_{\text {tot }} \geq 55 \mathrm{~dB}$} \\
\cline { 2 - 3 } \cline { 5 - 6 } Regression model & Road & Rail & & Road & Rail \\
\cline { 2 - 3 } $\begin{array}{l}\text { Semi-log } \\
\text { OLS }\end{array}$ & 1.17 & 0.36 & & 1.68 & 0.70 \\
$\quad$ Spatial lag & 1.15 & 0.34 & & 1.69 & 0.72 \\
Concave & & & & \\
$55 \mathrm{~dB}$ & 1.35 & 0.08 & & - \\
$60 \mathrm{~dB}$ & 1.70 & 0.28 & & - \\
$65 \mathrm{~dB}$ & 2.19 & 1.03 & & - \\
$70 \mathrm{~dB}$ & 2.90 & 4.09 & - & - \\
\hline NSDI $=|(\partial P / \partial L)(100 / P)|$ & & &
\end{tabular}

$\mathrm{NSDI}=|(\partial P / \partial L)(100 / P)|$ 